
allemande

51-1 | 2019

La République démocratique allemande dans l'espace public européen (1949-2018)

\title{
L'avènement de la Cour d'appel du Tribunal pénal fédéral de droit suisse
}

Chronique juridique

\section{Sandie Calme}

\section{OpenEdition \\ Journals}

Édition électronique

URL : https://journals.openedition.org/allemagne/1643

DOI : 10.4000/allemagne. 1643

ISSN : 2605-7913

Éditeur

Société d'études allemandes

\section{Édition imprimée}

Date de publication : 2 juillet 2019

Pagination : 259-263

ISSN : 0035-0974

Référence électronique

Sandie Calme, "L'avènement de la Cour d'appel du Tribunal pénal fédéral de droit suisse », Revue d'Allemagne et des pays de langue allemande [En ligne], 51-1 | 2019, mis en ligne le 02 juillet 2019, consulté le 03 juin 2022. URL : http://journals.openedition.org/allemagne/1643 ; DOI : https://doi.org/ 10.4000/allemagne.1643 


\section{Chronique juridique}

\section{L’avènement de la Cour d'appel du Tribunal pénal fédéral de droit suisse}

\section{- Sandie Calme*}

Dans le cadre d'une réforme majeure du droit pénal et de la procédure pénale suisses, le Tribunal pénal fédéral se dote d'une Cour d'appel, avec prise d'effet dès janvier 2019. Il s'agit du choix d'offrir aux justiciables un double degré de juridiction concernant une juridiction pénale dérogatoire. En effet, le droit pénal est considéré $a$ priori comme une matière relevant de la justice cantonale et le Tribunal pénal fédéral est compétent en la matière pour une série de domaines d'exception. Basiquement, au niveau cantonal, le double degré de juridiction auprès de juges du fond est traditionnellement offert. Cette option sera bientôt ouverte aux problématiques pénales spéciales du Tribunal pénal fédéral.

\section{Spécificités du Tribunal pénal fédéral}

Le Tribunal pénal fédéral est scindé en deux instances chargées chacune de compétences relevant de la matière pénale, la Cour des affaires pénales et la Cour des plaintes. Leurs attributions sont spécifiées par le Code de procédure pénale suisse et par la loi sur l'organisation des autorités pénales.

\section{A. La Cour des affaires pénales}

Ainsi, la Cour des affaires pénales (articles 23 et suivants du Code de procédure pénale suisse) traite des litiges relevant de la compétence fédérale, dont notamment certains contentieux criminels et correctionnels relatifs à la violation des intérêts fédéraux, des litiges impliquant des substances explosives, la criminalité financière d'envergure, des infractions se rapportant à des lois fédérales régaliennes, portant par exemple sur des activités belliqueuses, sur le nucléaire, les marchés financiers ou encore l'aviation.

* Docteur en droit, LL.M. (Francfort sur le Main, Allemagne), avocate au barreau de Paris. 


\section{B. La Cour des plaintes}

Pour sa part, la Cour des plaintes exerce des compétences spécifiques de niveau fédéral notamment en matière de détention provisoire, de mesures de contraintes, de décisions et ordonnances de la Cour des affaires pénales, de conflits de compétence entre les cantons et entre les cantons et la Confédération, de coopération pénale internationale et d'exécution des jugements pénaux.

La Cour des plaintes, dans sa décision du 6 novembre 2017, a eu l'occasion de s'exprimer ainsi, sur sa compétence:

«La Cour des plaintes, en tant qu'autorité de recours, examine avec plein pouvoir de cognition en fait et en droit les recours qui lui sont soumis. [...] Les tribunaux doivent trancher uniquement des questions concrètes et non pas prendre des décisions purement théoriques [...]. Le recourant doit ainsi être directement atteint dans ses droits par une décision qui lui cause une lésion et doit avoir un intérêt à ce que le préjudice causé par l'acte qu'il attaque soit éliminé.»

\section{Distinction de l'organisation juridictionnelle par rapport au droit français}

De la sorte, la catégorisation des juridictions pénales à l'échelle territoriale opérée par le droit suisse diffère de la conception traditionnelle et théorique du droit pénal français et de ses règles de procédure, qui organise les attributions des juridictions pénales territoriales sur la base de degrés de gravité des infractions en les classant en crimes, délits et contraventions, chacune de ces catégories d'infractions étant amenée à faire l'objet de procédures juridictionnelles distinctes: Cours d'assises pour les crimes, tribunaux correctionnels pour les délits pénaux, tribunaux de police pour les contraventions. S'il existe des situations où cette conceptualisation de compétence juridictionnelle axée sur le degré de gravité des infractions est altérée, ce principe de gradation est un principe fondamental de procédure pénale français auquel déroge d'emblée le Tribunal pénal fédéral.

\section{Légitimité de la nouvelle cour d'appel}

\section{A. Le projet}

La Cour d'appel du Tribunal pénal fédéral, issue de la réforme de la loi sur l'organisation des autorités pénales, qui entre en vigueur dès janvier 2019, est légitime.

\section{Un double degré de juridiction au fond}

La nouvelle Cour d'appel, de niveau fédéral, est dûment appelée à juger une seconde fois au fond des litiges portés devant le Tribunal pénal fédéral, ce qui institue un double degré de juridiction au fond. Il n'en demeure pas moins que le plus haut degré de juridiction du Tribunal fédéral, qui remplit la fonction de cour de cassation dont la compétence est limitée à juger à nouveau, mais seulement sur le droit et non au fond, est préservé.

\section{Des juges élus}

La Cour d'appel, à laquelle les procédures d'appel et de révision sont confiées, a pour président un magistrat nommé par la cour plénière et est composée de deux juges ordinaires à temps partiel, de plusieurs juges suppléants, choisis de préférence parmi les magistrats des tribunaux pénaux cantonaux de première ou de deuxième 
instance, élus par l'Assemblée fédérale, et elle pourra recourir à des juges de la Cour des plaintes.

L'élection des juges est un gage de légitimité de cette Cour d'appel, élection pour laquelle l'expérience pénale à l'échelle cantonale est mise en avant.

\section{B. En quoi il se distingue des cours d'appel françaises au pénal}

Ce nouveau système se distingue de celui des cours d'appel françaises en matière pénale, qui ne connaît pas le principe de l'élection des juges.

\section{Le principe du double degré de juridiction en matière pénale}

En droit français, le principe du double degré de juridiction au fond est exprimé au sein du Code de procédure pénale à la fois en matière criminelle, devant la Cour d'assises, en matière correctionnelle, devant le Tribunal correctionnel, ainsi que pour certains contentieux relatifs à des contraventions portées devant le Tribunal de police. Pour ces trois catégories, la Cour d'appel est le second degré de juridiction au fond.

\section{Le droit d'appel en matière criminelle}

Le droit d'appel en matière criminelle (depuis la loi du 15 juin 2000) est consacré aux articles 380-1 et suivants du Code de procédure pénale en ce qui concerne les Cours d'assises. Selon l'article 380-2 de ce code, la faculté d'appeler (devant une autre Cour d'assises autrement constituée) appartient à l'accusé, au ministère public, à la personne civilement responsable et à la partie civile, chacune en ce qui concerne ses intérêts civils, aux administrations publiques exerçant l'action publique en cas d'appel du ministère public et au procureur général quand il interjette appel des arrêts d'acquittement. Certains cas de figure procéduraux imposent à la Cour d'assises d'appel de ne pas aggraver le sort de l'appelant en matière de crimes.

\section{Le droit d'appel en matière correctionnelle}

En matière correctionnelle, sur le même modèle, le droit d'appel (article $496 \mathrm{du}$ Code de procédure pénale) appartient au prévenu, à la personne civilement responsable et à la partie civile, chacune en ce qui concerne ses intérêts civils, au procureur de la République, aux administrations publiques exerçant l'action publique, ainsi qu'au procureur général près la cour d’appel (article 497 du Code de procédure pénale).

Le principe du double degré de juridiction au fond est ainsi pleinement consacré en droit pénal français.

\section{Son originalité voire ses perspectives d'avenir}

La réforme instituant la Cour d'appel du Tribunal pénal fédéral est la consécration de la jurisprudence récente de la Cour européenne des droits de l'homme et d'une certaine analyse de son corpus normatif.

\section{La perspective du droit à la liberté et à la sûreté}

Sous l'angle du droit à la liberté et à la sûreté, la jurisprudence récente de la Cour européenne des droits de l'homme, tout en reconnaissant que, selon les termes de la Convention européenne de sauvegarde des droits de l'homme et des libertés fondamentales elle-même, le double degré de juridiction est seulement une faculté pour les États concernés, établit que l'exercice de cette faculté implique l'octroi des mêmes garanties en première instance et en appel. 
La Cour européenne des droits de l'homme s'est saisie de la question de la force du principe de double degré de juridiction en matière pénale, sur la base de l'article 5 $\$ 4$ (droit à la liberté et à la sûreté) de la Convention européenne de sauvegarde des droits de l'homme et des libertés fondamentales, selon lequel «toute personne privée de sa liberté par arrestation ou détention a le droit d'introduire un recours devant un tribunal, afin qu'il statue à bref délai sur la légalité de sa détention et ordonne sa libération si la détention est illégale». Selon la Cour européenne des droits de l'homme (l'affaire Ilnseher c. Allemagne, arrêt du 4 décembre 2018, Grande Chambre, requêtes $\mathrm{n}^{\circ} 10211 / 12$ et $\left.\mathrm{n}^{\circ} 27505 / 14\right)$,

«254. L’article $5 \$ 4$ n’astreint pas les États contractants à instaurer plus d'un degré de juridiction pour l'examen de la légalité de la détention et pour celui des demandes d'élargissement. Néanmoins, un État qui offre un second degré de juridiction doit en principe accorder aux détenus les mêmes garanties aussi bien en appel qu'en première instance (Navarra $c$. France, 23 novembre 1993, $\$ 28$, série A n² 273-B, Khoudobine c. Russie, n 59696/00, \$124, CEDH 2006-XII (extraits), et S.T.S. c. Pays-Bas, précité, \$43)».

\section{La perspective du droit à un double degré de juridiction}

Le droit à un double degré de juridiction fait partie intégrante du droit suisse.

Plus spécifiquement, c'est l'article 2 du Protocole n 7 à la Convention européenne des droits de l'homme et de sauvegarde des libertés fondamentales qui traite spécifiquement du droit au double degré de juridiction en matière pénale, selon ces termes:

"Article 2 - Droit à un double degré de juridiction en matière pénale: Toute personne déclarée coupable d'une infraction pénale par un tribunal a le droit de faire examiner par une juridiction supérieure la déclaration de culpabilité ou la condamnation. L'exercice de ce droit, y compris les motifs pour lesquels il peut être exercé, sont régis par la loi.

Ce droit peut faire l'objet d'exceptions pour des infractions mineures telles qu'elles sont définies par la loi ou lorsque l'intéressé a été jugé en première instance par la plus haute juridiction ou a été déclaré coupable et condamné à la suite d'un recours contre son acquittement.»

Le droit français, en ce qu'il consacre le principe de double degré de juridiction au fond en matière pénale, consacre l'application de cet article 2 du protocole $n^{\circ} 7$.

Ce protocole $\mathrm{n}^{\circ} 7$, qui fait l'objet de 44 ratifications étatiques, est entré en vigueur en Suisse le $1^{\text {er }}$ novembre 1988, et est associé à deux réserves et une déclaration émises par la Suisse, qui ne portent pas de dérogations au principe du double degré de juridiction. Il est également entré en vigueur en France à la même date, avec une déclaration qui n'affecte pas le concept de double degré de juridiction.

On pourrait associer cet article 2 du protocole $n^{\circ} 7$ de la Convention européenne de sauvegarde des droits de l'homme et des libertés fondamentales à la jurisprudence Ilnseher c. Allemagne du 4 décembre 2018 sur l'octroi aux détenus des mêmes garanties en appel et en première instance, pour en déduire la consécration actuelle du principe de double degré de juridiction au fond en matière pénale, qui serait de facto applicable en droit français et en droit suisse comme au sein des ordres juridiques des 44 États ayant ratifié le protocole $\mathrm{n}^{\circ} 7$, sur cette base normative et jurisprudentielle.

Concernant cet article 2 du protocole $n^{\circ} 7$, la Cour européenne des droits de l'homme condamne les États en cause dès lors que «l'exercice par le requérant de son droit à un double degré de juridiction se [...] fait au prix de sa liberté» (voir notamment: 
Rostovtsev c. Ukraine, 2728/16, quatrième section, le 25 juillet 2017; Firat c. Grèce, 46005/11, les 9 novembre 2017 et 9 février 2018). Il s'agit de situations où l'exercice même du droit à un double degré de juridiction fonde une privation de liberté illégale. Le droit au double degré de juridiction se présente ainsi comme étant le corollaire du droit à la liberté et à la sûreté.

En instituant la Cour d'appel du Tribunal pénal fédéral, la réforme de la loi sur l'organisation des autorités pénales s'inscrit dans le cadre de la jurisprudence très actuelle de la Cour européenne des droits de l'homme, redécouvre le protocole $\mathrm{n}^{\circ} 7$ de la Convention européenne de sauvegarde des droits de l'homme et des libertés fondamentales et converge avec l'analyse traditionnelle du droit français de la procédure pénale. Dans le contexte suisse, les juges de la nouvelle Cour d'appel sont élus au niveau parlementaire en privilégiant l'expérience acquise au niveau des fonctions juridictionnelles cantonales. Cette restructuration opérée en plaçant des juges issus de juridictions locales cantonales est à même d'opérer progressivement une refonte du droit pénal fédéral sur les matières régaliennes affectées à la Cour des affaires pénales et à la Cour des plaintes composant le Tribunal pénal fédéral, dans un souci d'harmonie voire d'unité de la jurisprudence pénale fédérale. 